\title{
EFICIÊNCIA DE RIZÓBIOS SOB DOSES DE FÓSFORO NA CULTURA DO FEIJÃO-CAUPI
}

\author{
Evaldo Morais da Silva ${ }^{1}$, Manoel Mota dos santos ${ }^{2}$, Marília Barcelos Souza Lopes ${ }^{3}$, Rodrigo Ribeiro \\ Fidelis ${ }^{4}$, Weslany Silva Rocha ${ }^{5}$, Aloísio Freitas chagas Júnior ${ }^{6}$
}

\begin{abstract}
RESUMO - O uso da adubação nitrogenada vem caindo em desuso em detrimento de vários fatores um deles é a Fixação Biológica de Nitrogênio (FBN). O feijão-caupi é uma cultura que responde bem à inoculação com estirpes de rizóbio previamente selecionadas. Objetivou-se com esse trabalho avaliar a biomassa de cultivares de feijão caupi em função das bactérias fixadora de nitrogênio submetidas ou não as doses de fósforo. Foram conduzidos dois ensaios em casa de vegetação, sendo um com a cultivar de feijão-caupi BRS Nova Era e outro com cv BRS Sempre Verde, com quatro estirpes de rizóbio associadas ou não a seis doses de fósforo. O experimento foi composto por cinco repetições, disposto em esquema fatorial 5 x 6 , sendo o primeiro fator correspondente à 4 estirpes de rizóbio: INPA 03-11B; R 48; BR 3277; BR 3299 mais um sem bactéria, o segundo fator à seis doses de adubo fosfatado: $0 ; 30 ; 60 ; 90 ; 120$ e $150 \mathrm{~kg} \mathrm{ha}^{-1}$ de $\mathrm{P}_{2} \mathrm{O}_{5}$. As características avaliadas foram: altura de planta, diâmetro de colo, massa seca da parte aérea, massa seca das raízes, número de nódulos e massa seca dos nódulos. As estirpes submetidas às doses de fósforo ou não proporcionaram acréscimo na altura de planta, diâmetro de colo, massa seca da parte aérea, massa seca da raiz para as duas cultivares. As estirpes que proporcionaram os melhores efeitos para as características de biomassa de modo geral foram: a INPA 03-11B, bem como, a estirpe BR 3299 para ambos cultivares a bactéria INPA 03-11B foi a que condicionou maior biomassa de modo geral. As doses de fósforo que apresentaram a máxima eficiência agronômica para as duas cultivares quando associadas as estirpes avaliadas variaram de 50 a $80 \mathrm{~kg} \mathrm{ha}^{-1} \mathrm{de}_{2} \mathrm{O}_{5}$ para a maioria das variáveis estudadas nesse trabalho.
\end{abstract}

Palavras chave: fixação biológica, P2O5, Vigna unguiculata.

\section{EFFICIENCY OF RHIZOBIAL STRAINS UNDER DOSES OF PHOSPHORUS IN TWO CULTIVARS OF COWPEA}

\begin{abstract}
The use of nitrogen fertilization is increasingly being discarded to the detriment of several factors. One of them is the Biological Fixation of Nitrogen (BNF), which is performed by bacteria known as rhizobia, which establish associations with plants and provide nitrogen fixed to the atmosphere $\left(\mathrm{N}_{2}\right)$ To the host mainly with legumes. Cowpea is a crop with high potential to be exploited and responds well to inoculation with previously selected strains of rhizobia. The objective of this work was to evaluate the biomass of cowpea cultivars as a function of nitrogen fixing bacteria submitted or not to phosphorus doses. Two trials were carried out under greenhouse conditions, one with BRS Nova Era cowpea cultivar and another with BRS Sempre Verde, with four rhizobia strains associated or not with six doses of phosphorus. The experiment was installed in a randomized complete block design with five replicates, arranged in a factorial scheme $5 \times 6$, being the first factor corresponds to 4 rhizobia strain INPA 03-11B; R 48; BR 3277; BR 3299 plus one without bacteria, the second factor to six doses of phosphate fertilizer: 0; 30; 60; 90; 120 and $150 \mathrm{~kg} \mathrm{ha}^{-1}$ of $\mathrm{P}_{2} \mathrm{O}_{5}$ totaling
\end{abstract}

\footnotetext{
${ }^{1}$ evaldomorais@ufpa.br; Campus Universitário do Tocantins (CUNTINS) - Universidade Federal do Pará (UFPA).

${ }^{2}$ santosmm@mail.uft.edu.br; Campus universitário de Gurupi - Universidade Federal do Tocantins (UFT).

${ }^{3}$ mariliabarcelosagro@hotmail.com; Campus universitário de Gurupi - Universidade Federal do Tocantins (UFT).

${ }^{4}$ fidelisrr@uft.edu.br; Campus universitário de Gurupi - Universidade Federal do Tocantins (UFT).

${ }^{5}$ weslanythd@hotmail.com; Campus universitário de Gurupi - Universidade Federal do Tocantins (UFT).

${ }^{6}$ chagasjraf@mail.com.br; Campus universitário de Gurupi - Universidade Federal do Tocantins (UFT).
} 
30 treatments. The characteristics evaluated in greenhouse were plant height, stem diameter, dry shoot mass, dry mass of the roots, number of nodules and dry mass of the nodules. Strains submitted to phosphorus doses or did not provide increase in plant height, shoot diameter, dry shoot mass, root dry mass for the two cultivars of BRS Nova Era and BRS Sempre Verde. The strains that provided the best effects for the biomass characteristics in general were: INPA 03-11B, as well as, the strain BR 3299 for the cultivar Nova Era, to cultivate Evergreen the bacterium INPA 03-11B was the one that conditioned Biomass in general. Phosphorus doses that presented the maximum agronomic efficiency for the two cultivars when associated with the strains evaluated ranged from 50 to $80 \mathrm{~kg} \mathrm{ha}^{-1}$ of $\mathrm{P}_{2} \mathrm{O}_{5}$ for most of the variables studied in this study.

Keywords: biological fixation, P2O5, Vigna unguiculata.

\section{INTRODUÇÃO}

No Brasil o cultivo do feijão-caupi (Vigna unguiculata (L.) Walp.) é uma das alternativas para geração de empregos em populações de baixa renda, sendo cultivado basicamente em pequenas propriedades das regiões norte e nordeste como atividade de subsistência, embora, já esteja sendo explorado em grandes áreas com adoção de tecnologias (Bastos et al., 2012). Essa cultura também tem se tornado atrativo para o agronegócio, com cultivos em grandes lavouras, sobretudo na safrinha, após o cultivo de soja ou milho (Cravo et al., 2009).

Devido ao ciclo curto e ao volume de solo explorado pelas raízes de feijoeiro, a baixa disponibilidade de nutrientes no solo é um dos principais fatores limitantes da produtividade. Devido ao alto teor de nitrogênio (N) nos grãos e demais tecidos, este é o nutriente mais extraído e exportado pela planta que tem como fontes: matéria orgânica, fertilizantes nitrogenados, via precipitação e a fixação biológica de $\mathrm{N}_{2}$ (Oliveira, 2013).

Apesar da sua importância o uso da adubação nitrogenada vem sendo cada vez mais descartada em detrimento de suas altas perdas no solo por lixiviação, volatilização e imobilização e pela introdução de novas tecnologias mais eficientes e menos agressivas ao meio ambiente (Azeem et al., 2014).

Uma das alternativas é a Fixação Biológica de Nitrogênio (FBN) que é realizada por bactérias conhecidas como rizóbios as quais estabelecem associações com plantas e fornecem nitrogênio fixado da atmosfera $\left(\mathrm{N}_{2}\right)$ para o hospedeiro, principalmente com leguminosas.

O feijão-caupi tem se mostrado bastante eficiente em relação a essa tecnologia de baixo custo. No entanto, vários fatores podem influenciar nesse processo biológico como fatores, edáficos e climáticos, além daqueles relacionados com a planta hospedeira e com a população nativa de bactérias fixadoras de nitrogênio nodulíferas em leguminosas limitando a FBN (Moreira $\&$ Siqueira, 2006). Esses fatores limitantes podem atuar sobre a bactéria e sobre o hospedeiro, afetando a simbiose, e seus efeitos também podem variar, dependendo das espécies de simbiontes envolvidas. Os fatores abióticos alteram quantitativa e qualitativamente a população de rizóbio no solo (Antón, 2004; Figueiredo et al., 2007).

Dentre os fatores edáficos um dos que vem sendo estudado com bastante ênfase é a adubação fosfatada que além de participar de vários processos fisiológicos nas plantas auxilia na nodulação e consequentemente otimiza o processo da FBN. O fósforo $(\mathrm{P})$ desempenha importante papel nas plantas, pois participa da constituição do ATP e de enzimas; quando em baixos teores no solo, a planta tem seu crescimento prejudicado (Kimani \& Derera, 2009).

Segundo Pastorini et al. (2000), para o feijão caupi, o fósforo tem proporcionado frequentes respostas, e sua baixa disponibilidade no solo, afeta negativamente o crescimento das plantas e sua produção. É conhecida a importância do fósforo na melhoria do estado nutricional das leguminosas, pois melhora a eficiência da simbiose rizóbio e leguminosa, estimulando a iniciação da formação dos nódulos, aumentando o peso e o número de nódulos, estimulando o crescimento das raízes e da parte aérea das plantas (Abdel-Wahab et al., 1994).

Objetivou-se com esse trabalho avaliar a biomassa de cultivares de feijão caupi em função das estirpes rizobianas associadas ou não a doses de fósforo, no sul do estado do Tocantins.

\section{MATERIAL E MÉTODOS}

O experimento foi conduzido em casa de vegetação na Estação Experimental da Universidade Federal do 
Tocantins, campus universitário de Gurupi, Estado do Tocantins, caracterizada pelas coordenadas geográficas $11^{\circ} 46^{\prime} 25.9^{\prime \prime}$ de latitude sul e $49^{\circ} 03^{\prime} 06^{\prime \prime}$ de longitude oeste, numa altitude de $293 \mathrm{~m}$, em solo do tipo Latossolo Vermelho-Amarelo Distrófico (EMBRAPA, 2013) com vasos de 4 litros de volume.

Antes da semeadura, coletou-se uma amostra de solo composta e realizou-se a caracterização física e química, onde foram encontrados os seguintes valores: $0,3 \mathrm{cmol}_{\mathrm{c}} \mathrm{dm}^{-3} \mathrm{de} \mathrm{Ca} ; 0,2 \mathrm{cmol}_{\mathrm{c}} \mathrm{dm}^{-3} \mathrm{de} \mathrm{Mg} ; 0,04 \mathrm{cmol}_{\mathrm{c}}$ $\mathrm{dm}^{-3}$ de $\mathrm{K} ; 0,05 \mathrm{mg} \mathrm{dm}^{-3}$ de P; $0,00 \mathrm{cmol}_{\mathrm{c}} \mathrm{dm}^{-3} \mathrm{de} \mathrm{Al}$; $2,59 \mathrm{cmol}_{\mathrm{c}} \mathrm{dm}^{-3} \mathrm{de} \mathrm{CTC} ; 0,54 \mathrm{cmol}_{\mathrm{c}} \mathrm{dm}^{-3} \mathrm{de} \mathrm{SB} ; 21 \%$ de V; pH 5,3 em $\mathrm{CaCl}_{2}$; matéria orgânica 1,1 dag kg'; areia $435 \mathrm{~g} \mathrm{~kg}^{-1}$; silte $50 \mathrm{~g} \mathrm{~kg}^{-1}$; argila $515 \mathrm{~g} \mathrm{~kg}^{-1}$.

Foram conduzidos dois ensaios em casa de vegetação, sendo um com a cultivar de feijão-caupi BRS Nova Era e outro com cv BRS Sempre Verde, com quatro estirpes de rizóbio associadas ou não a seis doses de fósforo. $\mathrm{O}$ experimento foi instalado em delineamento em blocos casualizados com cinco repetições, disposto em esquema fatorial $5 \times 6$, sendo o primeiro fator correspondente à 4 estirpes de Bradyrhizobium japonicum (INPA 03-11B; R 48; BR 3277; BR 3299) mais um sem a bactéria, e o segundo fator à seis doses de adubo fosfatado, superfosfato simples: $0 ; 30 ; 60 ; 90 ; 120 \mathrm{e} 150 \mathrm{~kg} \mathrm{ha}^{-1} \mathrm{de}_{2} \mathrm{O}_{5}$ totalizando 30 tratamentos.

Após crescimento em meio YMA (extrato de levedura, manitol, agar) por cinco dias, foram suspensas individualmente em solução salina $\left(0,2 \% \mathrm{MgSO}_{4}\right)$ e adicionadas na concentração de $10^{9}$ células $\mathrm{mL}^{-1}$ cada, às sementes duas horas antes da semeadura, sendo utilizada $50 \mathrm{~mL} \mathrm{~kg}^{-1}$ de semente.

O tratamento de sementes foi realizado utilizando inseticida com o princípio ativo Tiametoxam, grupo químico dos neonicotinóides e com recomendações para a cultura de 200 a $300 \mathrm{ml}$ para $100 \mathrm{~kg}$ sementes. E o fungicida com o princípio ativo Tiofanato metilico+fluazinam, pertencente aos grupos químicos Benzimidazol (precursor de Tiofanato-Metílico) e Fenilpiridinilamina (percursor de Fluazinam), com recomendações para a cultura de 145 a $180 \mathrm{ml}$ para $100 \mathrm{~kg}$ de sementes.

Foi realizada a adubação complementar de $50 \mathrm{~kg}$ $\mathrm{ha}^{-1} \mathrm{de}_{2} \mathrm{O}$ usando como fonte o Cloreto de potássio $(\mathrm{KCl})$ e de $20 \mathrm{~kg} \mathrm{ha}^{-1}$ de $\mathrm{N}$ com fonte ureia $45 \%$ de $\mathrm{N}$ para adubação nitrogenada na semeadura.

A semeadura foi realizada de forma manual, com quatro sementes por vasos posteriormente, foi realizado o desbaste das plantas 10 dias após a emergência, mantendo uma densidade final de duas plantas por vaso. Aos 45 dias após a emergência (45DAE), o experimento foi encerrado com mensurações das seguintes características: altura da planta, diâmetro do colo, massa seca da parte aérea, massa seca radicular, massa seca de nódulos e número de nódulos.

O diâmetro do colo foi obtido com paquímetro digital e a altura com régua milimétrica, tomando-se como padrão a gema terminal (meristema apical). A quantificação da massa seca da parte aérea, massa seca do sistema radicular e de nódulos, foi realizada através da pesagem das partes vegetais em (gramas), após a secagem em estufa de circulação de ar forçada a 65 ${ }^{\circ} \mathrm{C}$, por um período de aproximadamente $72 \mathrm{~h}$, até atingir peso constante.

Os dados obtidos foram submetidos à análise de variância, e ao teste $\mathrm{F}$ e quando significativos utilizouse a análise de regressão. A seleção dos modelos foi baseada na significância dos betas e no maior coeficiente de determinação $\left(\mathrm{R}^{2}\right)$, para plotagem dos gráficos utilizando-se o programa Sigma Plot versão 10.0. Para os dados estatísticos foi utilizado o programa computacional SISVAR versão 5.6 (Ferreira, 2011).

\section{RESULTADO E DISCUSSÃO}

Na Tabela 1 observou-se que houve interação significativa entre os fatores estudados para todas as variáveis, tanto para cv BRS Nova Era como cv BRS Sempre Verde. Indicando que as estirpes estudadas influenciaram de forma diferenciada no comportamento das cultivares quando submetidas às doses de fósforo.

Em relação ao efeito dos tratamentos para altura de planta, observou-se que todas as estirpes foram superiores ao tratamento testemunha, em todos os níveis de fósforo exceto na dose 60,90 e 120 para a estirpe BR3299. A altura máxima estimada das plantas foi de $32,22 \mathrm{~cm}$, sendo a dose de $82,85 \mathrm{~kg} \mathrm{ha}^{-1}$ de $\mathrm{P}_{2} \mathrm{O}_{5}$ aquela que promoveu este ponto de máxima na cv BRS Nova Era (Figura 1) associada à estirpe INPA 03-11B, apresentando aumento percentual de 31,08\% em relação ao tratamento testemunha (S/B) para mesma dose e; a menor altura foi observada na dose $0 \mathrm{~kg} \mathrm{ha}^{-1} \mathrm{de}_{2} \mathrm{O}_{5}$, evidenciando que à ausência de fósforo 
Tabela 1 - Resumo da análise de variância para as variáveis estudadas de plantas de feijão-caupi, cv. BRS Nova Era e cv. BRS Sempre, em função das estirpes submetidas ou não a seis doses de fósforo (P) em casa de vegetação. Gurupi-TO, 2015

\begin{tabular}{|c|c|c|c|c|c|c|c|}
\hline \multicolumn{8}{|c|}{ Ensaio 1: cv BRS Nova Era } \\
\hline \multicolumn{8}{|c|}{ Quadrado Médio } \\
\hline F.V. & GL & $\mathrm{AP}(\mathrm{cm})$ & $\mathrm{DC}(\mathrm{mm})$ & $\operatorname{MSPA}(\mathrm{g})$ & $\operatorname{MSR}(g)$ & NN (uni) & $\operatorname{MSN}(g)$ \\
\hline Bloco & 4 & 0,4516 & 0,2585 & 0,0034 & 0,00016 & 0,0639 & 0,00000 \\
\hline Inoculante (I) & 4 & $217,3706^{* *}$ & $4,9118 * *$ & $2,6099 * *$ & $0,1306^{* *}$ & $103,8061 * *$ & $0,000942 * *$ \\
\hline Doses P(D) & 5 & $200,3878 * *$ & $0,6059 * *$ & $1,0162 * *$ & $0,1272 * *$ & $57,8738^{* *}$ & $0,0004 * *$ \\
\hline I $\times \mathrm{D}$ & 20 & $17,6179 * *$ & $0,2177 * *$ & $0,1495 * *$ & $0,0150 * *$ & $31,6470 * *$ & $0,0002 * *$ \\
\hline Resíduo & & 0,0341 & 0,0122 & 0,0022 & 0,00014 & 0,0466 & $7,3020 \mathrm{E}^{-0023}$ \\
\hline Média & & 24,78 & 3,9852 & 0,9082 & 0,4101 & 3,0923 & 0,0093 \\
\hline $\mathrm{CV}$ & & 0,75 & 2,77 & 5,19 & 2,92 & 6,98 & 0,0000 \\
\hline \multicolumn{8}{|c|}{ Ensaio 2: cv BRS Sempre Verde } \\
\hline Bloco & 4 & 0,9818 & 0,1877 & 0,0246 & 0,0160 & 0,0135 & 0,000017 \\
\hline Inoculante (I) & 4 & $762,2096 * *$ & $5,2236 * *$ & $5,2657 * *$ & $0,0724 * *$ & $3,0364 * *$ & $0,000092 * *$ \\
\hline Doses P(D) & 5 & $201,4779 * *$ & $0,6552 * *$ & $0,7409 * *$ & $0,1250 * *$ & $6,5568 * *$ & $0,000056^{* *}$ \\
\hline $\begin{array}{l}\text { I x D } \\
\text { Resíduo }\end{array}$ & 20 & $\begin{array}{c}30,7973 * * \\
0,0961\end{array}$ & $\begin{array}{c}0,4516^{* *} \\
0,0707\end{array}$ & $\begin{array}{c}0,2703 * * \\
0,0308\end{array}$ & $\begin{array}{c}0,0332 * \\
0,0196\end{array}$ & $\begin{array}{c}3,9988 * * \\
0,0251\end{array}$ & $\begin{array}{c}0,000050^{* *} \\
0,000010\end{array}$ \\
\hline Média & & 27,1039 & 3,3238 & 0,9783 & 0,4473 & 2,8660 & 0,0124 \\
\hline $\mathrm{CV}$ & & 1,14 & 8,0 & 17,94 & 31,37 & 5,54 & 26,05 \\
\hline
\end{tabular}

AP - altura de planta, MSPA - massa seca da parte aérea, DC- diâmetro de colo, MSR- massa seca da raiz, NN - número de nódulos, MSN - massa seca dos nódulos ** significativo para $\mathrm{P}$ d” 0,01 ; *significativo para $\mathrm{P} \leq 0,05$ pelo teste $\mathrm{F}$.

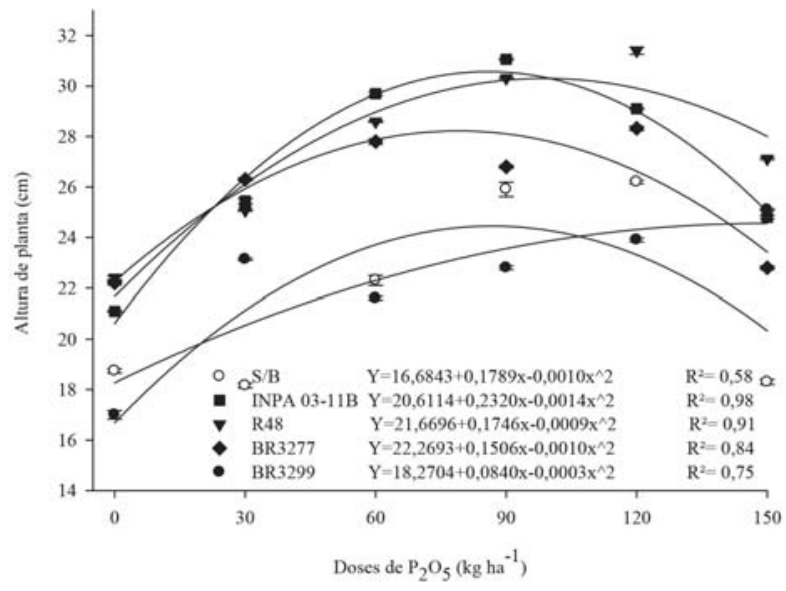

Figura 1 - Altura de planta de feijão-caupi, BRS Nova Era, em função das estirpes submetidas as doses crescentes de $\mathrm{P}_{2} \mathrm{O}_{5}$ no município de Gurupi-TO, 2015.

é um fator limitante ao crescimento de feijão-caupi (Coutinho et al., 2014).

Para a cv. BRS Sempre Verde o ponto de máxima eficiência foi obtido na dose de $57,68 \mathrm{~kg} \mathrm{ha}^{-1}$ de $\mathrm{P}_{2} \mathrm{O}_{5}$ e altura estimada de 37,84 cm com a estirpe INPA 0311B (Figura 2). Enquanto o valor estimado da altura de planta da testemunha para a mesma dose foi de 36,42. A análise da altura é importante na avaliação da qualidade de plantas, uma vez que fornece um bom indicador de evolução da cultura (Souto et al., 2009).

Observou-se que ao aumentar as doses de fósforo aumentou a altura da planta, chegando ao ponto de máxima eficiência e em seguida ocorreu a diminuição, provavelmente, se dá ao fato de que a planta de feijão-caupi quando submetida a elevadas doses de P passa a ter seu crescimento reduzido, fazendo com que o fósforo em excesso torne-se um fator negativo para o crescimento do feijão-caupi (Coutinho et al., 2014).

Para o diâmetro de colo na cv. BRS Nova Era (Figura 3 ) as estirpes que condicionaram maior diâmetro foram INPA 03-11B, R 48 e BR 3277, respectivamente, as quais foram superiores a testemunha $(\mathrm{S} / \mathrm{B})$, sendo que a maior média estimada foi proporcionada pela INPA 03-11B, apresentando $4,51 \mathrm{~mm}$ de diâmetro de colo na dose de $73,67 \mathrm{~kg} \mathrm{ha}^{-1}$ de $\mathrm{P}_{2} \mathrm{O}_{5}$ já a testemunha foi de $4,16 \mathrm{~mm}$ para mesma dose. 
Enquanto que a cultivar BRS Sempre Verde (Figura 4) observou-se que as estirpes INPA 03-11B e BR 3299 foram superiores a testemunha $(\mathrm{S} / \mathrm{B})$. A maior média estimada do diâmetro de colo foi condicionada pela INPA 03-11B com 4,48mm na dose de $87,5 \mathrm{~kg} \mathrm{ha}^{-1}$ de $\mathrm{P}_{2} \mathrm{O}_{5}$ enquanto a testemunha $(\mathrm{S} / \mathrm{B})$ foi de 3,48 para a mesma dose, apresentando aumento de $28,73 \%$ em relação a testemunha. $\mathrm{Na}$ dose $0 \mathrm{~kg} \mathrm{ha}^{-1}$ de $\mathrm{P}_{2} \mathrm{O}_{5}$ associado ou não as bactérias obtiveram se as menores médias

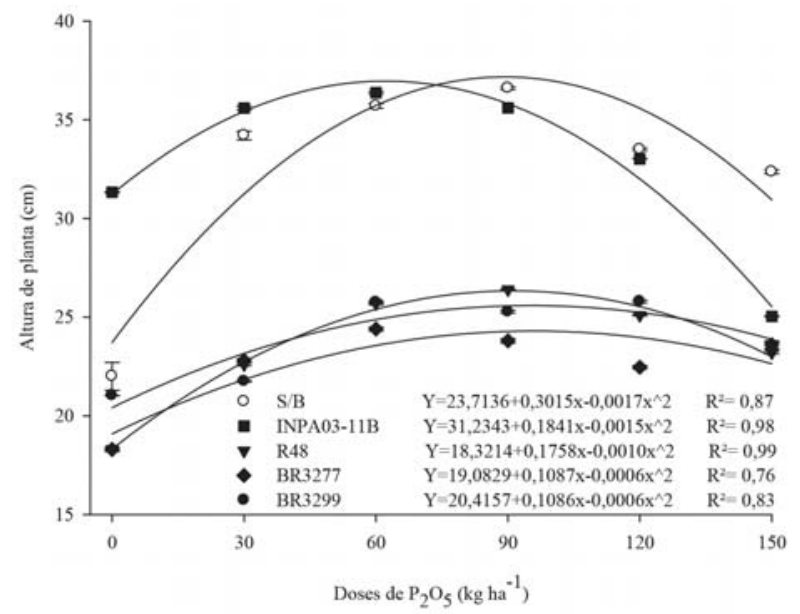

Figura 2 - Altura de planta de feijão-caupi cv.BRS Sempre Verde, em função das estirpes submetidas as doses crescentes de $\mathrm{P}_{2} \mathrm{O}_{5}$ no município de Gurupi- TO, 2015.

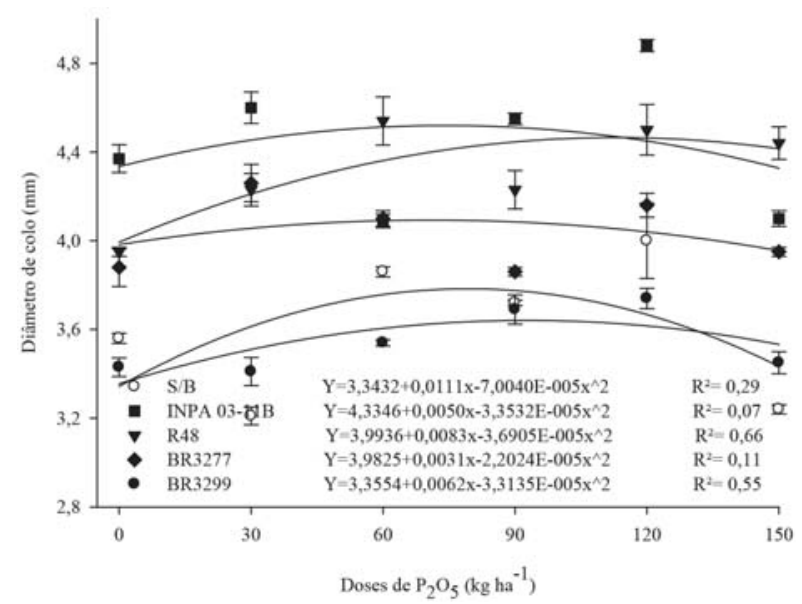

Figura 3 - Diâmetro de colo de planta de feijão-caupi, BRS Nova Era, em função das estirpes submetidas as doses crescentes de $\mathrm{P}_{2} \mathrm{O}_{5}$ no município de Gurupi- TO, 2015. tanto para cv. BRS Nova Eram quanto a cv. BRS Sempre Verde (Figuras 3 e 4), evidenciando o efeito positivo do uso da adubação fosfatada associada ou não as bactérias fixadoras de nitrogênio. Oliveira et al. (2011) também evidenciaram o efeito positivo do $\mathrm{P}$ no diâmetro do colmo, indicando relação do P com o aumento da resistência da planta ao acamamento.

Quanto a massa seca da parte aérea na cv. BRS Nova Era (Figura 5), todas as estirpes proporcionaram



Figura 4 - Diâmetro de colo de planta de feijão-caupi, BRS Sempre Verde, em função das estirpes submetidas as doses crescentes de $\mathrm{P}_{2} \mathrm{O}_{5}$ no município de Gurupi- TO, 2015.

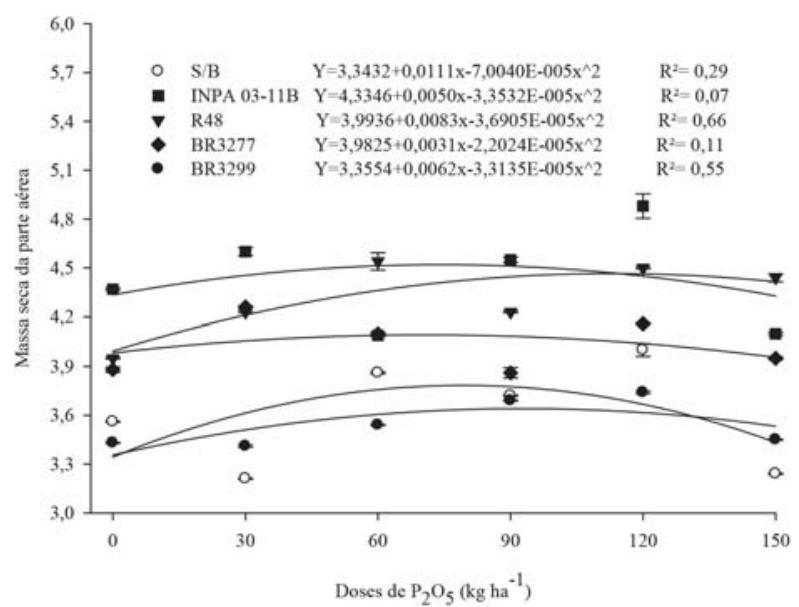

Figura 5 - Massa seca da parte aérea de planta de feijãocaupi, BRS Nova Era, em função das estirpes submetidas as doses crescentes de $\mathrm{P}_{2} \mathrm{O}_{5}$ no município de Gurupi- TO, 2015. 
as maiores médias nas diferentes doses em relação à testemunha, com exceção da estirpe BR 3299, na dose 0 e $120 \mathrm{~kg} \mathrm{ha}^{-1}$ de $\mathrm{P}_{2} \mathrm{O}_{5}$. Observa-se que a dose de $90 \mathrm{~kg} \mathrm{ha}^{-1}$ de $\mathrm{P}_{2} \mathrm{O}_{5}$ foi a que melhor diferenciou o efeito das estirpes e na $0 \mathrm{~kg} \mathrm{ha}^{-1}$ de $\mathrm{P}_{2} \mathrm{O}_{5}$, percebese as menores médias para maioria das estirpes demonstrando o efeito sinérgico da adubação fosfata sob as estirpes para incremento da massa seca da parte aérea. A maior média estimada foi condicionada pela estirpe INPA 03-11B, com 1,75g na dose de $107 \mathrm{~kg} \mathrm{ha}^{-1}$ de $\mathrm{P}_{2} \mathrm{O}_{5}$ já para a testemunha a média estimada foi de $0,36 \mathrm{~g}$ para a mesma dose, sendo que a bactéria foi superior ao tratamento testemunha aproximadamente 5 vezes. Soares et al. (2006) trabalhando com diferentes estipes de Bradyrhizobium, também obtiveram maior produção de fitomassa seca da parte aérea quando as sementes foram inoculadas com a estipe INPA 03-11B, quando foram comparadas apenas as demais estirpes.

Para a massa seca da parte aérea na cv. BRS Sempre Verde (Figura 6) observou-se que o tratamento testemunha sem bactéria $(\mathrm{S} / \mathrm{B})$ condicionou as maiores médias quando comparado com os tratamentos que tinham inoculante mais doses de $\mathrm{P}_{2} \mathrm{O}_{5}$, exceto para estirpe INPA 03-11B. Isto demonstra que a cultivar e muito eficiente na absorção de P no solo oriundo da adubação fosfatada indicando sua independência da inoculação com rizóbio para absorção de P (Rocha, 2016). Dentre as estirpes a INPA 03-11B foi a que melhor se destacou apresentando média estimada da MSPA de 1,69g na dose de 71,03 $\mathrm{kg} \mathrm{ha}^{-1}$ de $\mathrm{P}_{2} \mathrm{O}_{5}$. Silva et al. (2010) observaram valores inferiores ao encontrado neste trabalho onde o valor máximo encontrado foi de $1,16 \mathrm{~g}$ de massa seca da parte aérea na dose $72 \mathrm{~kg} \mathrm{ha}^{-1}$ de $\mathrm{P}_{2} \mathrm{O}_{5}$ Enquanto o tratamento testemunha, apresentou média máxima estimada de $2,27 \mathrm{~g}$ para a dose de $127 \mathrm{~kg} \mathrm{ha}^{-1}$ de $\mathrm{P}_{2} \mathrm{O}_{5}$.

$\mathrm{Na}$ dose $0 \mathrm{~kg} \mathrm{ha}^{-1}$ de $\mathrm{P}_{2} \mathrm{O}_{5}$ e sem inoculante foi observada as menores médias para massa seca da parte aérea demonstrando a importância da adubação fosfatada e o uso de estirpes eficiente no processo de fixação biológica de nitrogênio. Guedes et al. (2010) avaliando eficiência agronômica de inoculantes em feijão-caupi no município de Pombal - PB observaram que a interação de bactérias fixadora de $\mathrm{N}_{2}$ com suplementação de fósforo permitiram maior aumento da massa seca da parte aérea. Isso se deve ao fato de que a maior disponibilidade de $\mathrm{P}$ favorece o crescimento da planta, por promover maior emissão e crescimento de folhas e maior área foliar da cultura, consequentemente, maior captação da radiação solar e incremento na produção de fotoassimilados (BONFIM-SILVA et al., 2011).

No que se refere a massa seca das raízes na cv. BRS Nova Era (Figura 7), observou-se que as estirpes INPA 03-11B e BR 3277 foram superiores as demais incluindo o tratamento testemunha (S/B), sendo observadas as maiores médias para massa seca das raízes.

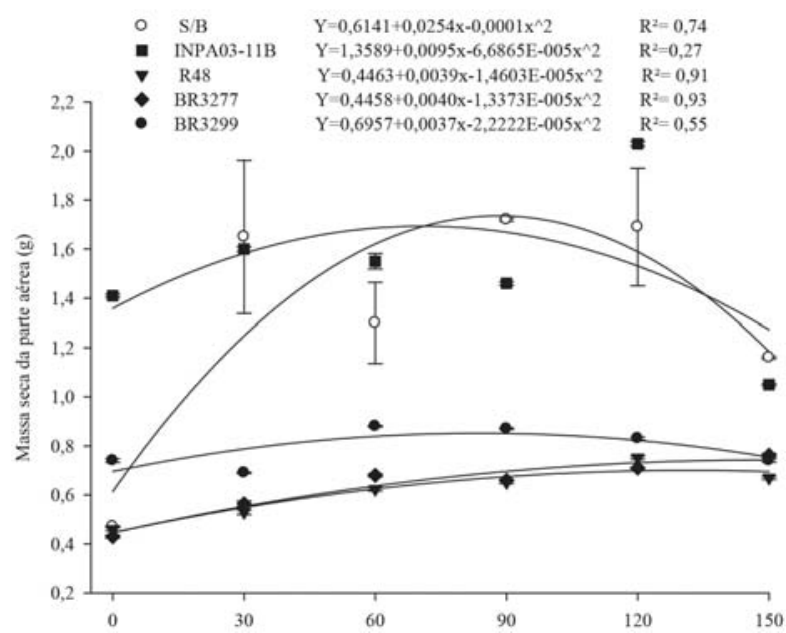

Figura 6 - Massa seca da parte aérea de planta de feijãocaupi, BRS Sempre Verde, em função das estirpes submetidas as doses crescentes de $\mathrm{P}_{2} \mathrm{O}_{5}$ no município de Gurupi- TO, 2015.

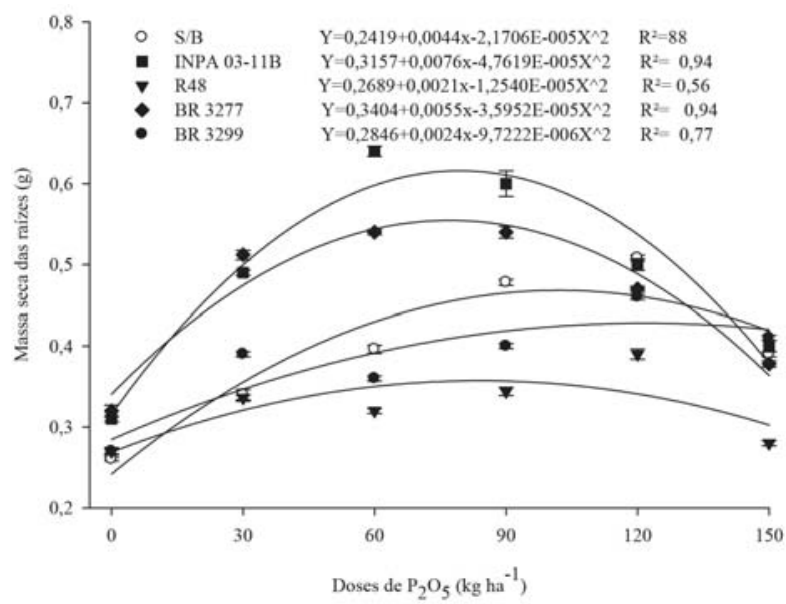

Figura 7 - Massa seca das raízes de planta de feijãocaupi, BRS Nova Era, em função das estirpes submetidas as doses crescentes de $\mathrm{P}_{2} \mathrm{O}_{5}$ no município de Gurupi- TO, 2015. 
A massa seca das raízes apresentou resposta quadrática tanto para o tratamento testemunha (S/B), bem como à interação da adubação fosfatada e inoculante, com a dose de máxima eficiência agronômica de $79,80 \mathrm{~kg} \mathrm{ha}^{-1}$ de $\mathrm{P}_{2} \mathrm{O}_{5}$ obtendo $0,61 \mathrm{~g}$ para a estirpe INPA 03-11B e 76,49 $\mathrm{kg} \mathrm{ha}^{-1}$ de $\mathrm{P}_{2} \mathrm{O}_{5}$ obtendo $0,55 \mathrm{~g}$ para estirpe $\mathrm{BR} 3277$. O tratamento testemunha contendo apenas adubação fosfatada (S/B) a dose de máxima eficiência estimada foi $101,35 \mathrm{~kg} \mathrm{ha}^{-1}$ de $\mathrm{P}_{2} \mathrm{O}_{5}$ obtendo $0,46 \mathrm{~g}$ de massa seca das raízes. Na dose $0 \mathrm{~kg} \mathrm{ha}^{-1} \mathrm{de}$ $\mathrm{P}_{2} \mathrm{O}_{5}$ foram observadas as menores médias. Assim, a maior disponibilidade de $\mathrm{P}$ favoreceu maior peso de massa seca das raízes bem como sua interação com os rizóbios proporcionando maior peso com menores doses de $\mathrm{P}_{2} \mathrm{O}_{5}$.

O fósforo auxilia no processo de nodulação pela transferência de energia na forma de Adenosina Trifosfato - ATP e aumenta o número de pelos radiculares proporcionando mais sítios de infecção para as bactérias fixadoras de $\mathrm{N}_{2}$ (Okeleye \& Okelana, 1997).

Chagas Junior et al. (2014) avaliando a eficiência da inoculação combinada de rizóbio e trichoderma em diferentes cultivares de feijão-caupi no Cerrado, observaram efeito significativo no incremento de raiz para o uso de rizóbios quando comparados aos tratamentos que não foram inoculados e sendo igual aos tratamentos que recebem adubação nitrogenada.

Na cultivar BRS Sempre Verde (Figura 8) o tratamento testemunha (S/B) foi superior a todas as estirpes exceto

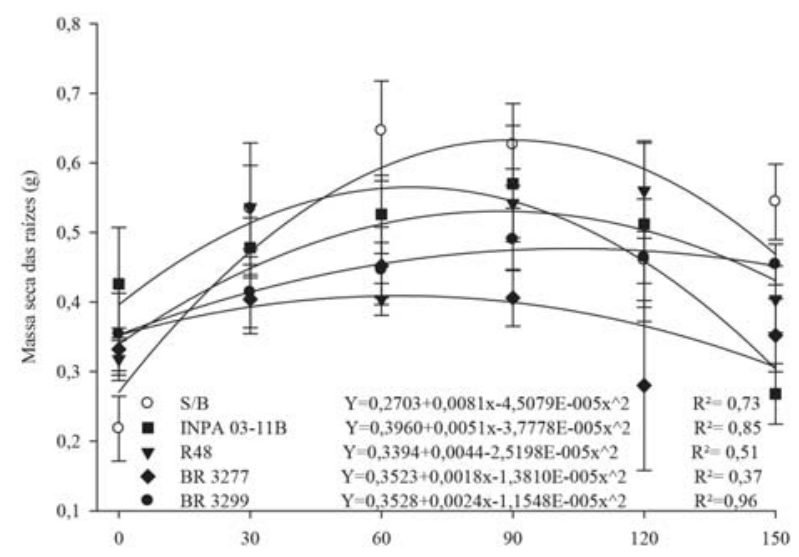

Figura 8 - Massa seca das raízes de planta de feijãocaupi cv. BRS Sempre Verde, em função das estirpes submetidas as doses crescentes de $\mathrm{P}_{2} \mathrm{O}_{5}$ no município de Gurupi- TO, 2015. nas doses 0 e $120 \mathrm{~kg} \mathrm{ha}^{-1}$ de $\mathrm{P}_{2} \mathrm{O}_{5}$, com relação as estirpes a que melhor se destacou foi a INPA03-11B a qual teve o valor máximo estimado para massa seca das raízes de $0,56 \mathrm{~g}$ na dose $67,49 \mathrm{~kg} \mathrm{ha}^{-1} \mathrm{de}_{2} \mathrm{O}_{5}$, para o tratamento testemunha foi de $0,63 \mathrm{~g}$ na dose $89,84 \mathrm{~kg} \mathrm{ha}^{-1}$ de $\mathrm{P}_{2} \mathrm{O}_{5}$. Essas maiores respostas da massa seca das raízes com o tratamento testemunha contendo apenas adubação fosfatada em relação aos tratamentos que além da adubação fosfatada receberam inoculante podem estar associada à especificidade da cultivar com o simbionte, mostrando menor interação quando comparado com a cv. BRS Nova Era a qual se observou incremento da massa seca das raízes quando ocorreu a associação das bactérias com a adubação fosfatada para esta característica avaliada.

Em relação o número de nódulos da cv. BRS Nova Era (Figura 9) observou-se que todas as estirpes estudadas foram capazes de nodular o feijão-caupi. Já o tratamento testemunha (S/B) não apresentou nodulação, isso comprova a maior capacidade nodulífera das estirpes estudas em relação às estirpes nativas para esta cultivar. O maior número de nódulos foi observado quando houve inoculação com as estirpes INPA 03-11B, R 48 e BR 3277, na qual a dose $150 \mathrm{~kg} \mathrm{ha}^{-1} \mathrm{P}_{2} \mathrm{O}_{5}$ proporcionou maior número de nódulos com a estirpe INPA 03-11B, com valor estimado de 10,5 nódulos; já para estirpe $\mathrm{R} 48$ observou o maior número na dose de $90 \mathrm{~kg} \mathrm{ha}^{-1} \mathrm{P}_{2} \mathrm{O}_{5}$ com o valor estimado de 8,65 nódulos.

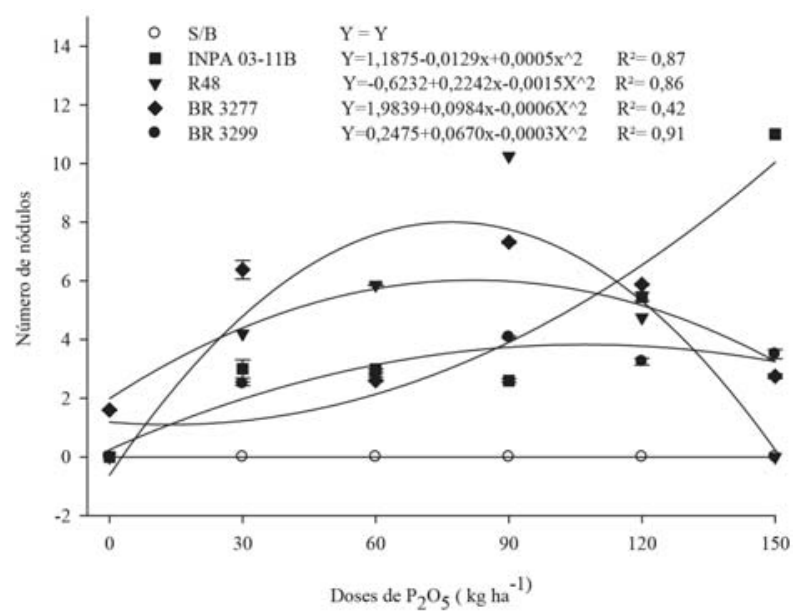

Figura 9 - Número de nódulos de planta de feijão-caupi, BRS Nova Era, em função das estirpes submetidas as doses crescentes de $\mathrm{P}_{2} \mathrm{O}_{5}$ no município de Gurupi- TO, 2015. 
O menor número de nódulos foi observado na dose de $0 \mathrm{~kg} \mathrm{ha}^{-1} \mathrm{P}_{2} \mathrm{O}_{5}$, o que já era esperado tendo em vista que o $\mathrm{P}$ é muito importante para o crescimento e desenvolvimento das raízes que são os locais onde ocorre a infecção e consequentemente nodulação das estirpes. Amaral et al. (2013) avaliando a produtividade e nodulação do feijão-caupi inoculado em função de fósforo e potássio verificaram que o uso de $\mathrm{P}$ promoveu maior número de nódulos. Isso ocorre devido o fósforo fazer parte do processo simbiótico, ajudando na formação e crescimento do nódulo uma vez que esse processo inicial exige um gasto energético grande (Burity et al., 2000)

Na cv. BRS Sempre Verde (Figura 10) o número de nódulos foi influenciado pela interação das estirpes fixadora de nitrogênio com as doses de fósforo sendo que o maior número de nódulos foi observado na dose de $60 \mathrm{~kg} \mathrm{ha}^{-1} \mathrm{de}_{2} \mathrm{P}_{5}$ com a estirpe BR 3299 com valor estimado de 4,78 nódulos. O fósforo é muito importante, pois melhora a nodulação, associação simbiótica entre o rizóbio e planta hospedeira e consequentemente melhora a fixação de $\mathrm{N}_{2}$ (Nyoki \& Ndakidemi, 2013).

Na dose $0 \mathrm{~kg} \mathrm{ha}^{-1} \mathrm{P}_{2} \mathrm{O}_{5}$ mesmo sem a presença de $\mathrm{P}$ ocorreu a nodulação. Isto demonstra a eficiência e capacidade nodulíferas dessas cepas de bactérias, isso implica dizer que as estirpes nativas foram capazes de infectar as raízes do feijão-caupi cv. BRS Sempre Verde.

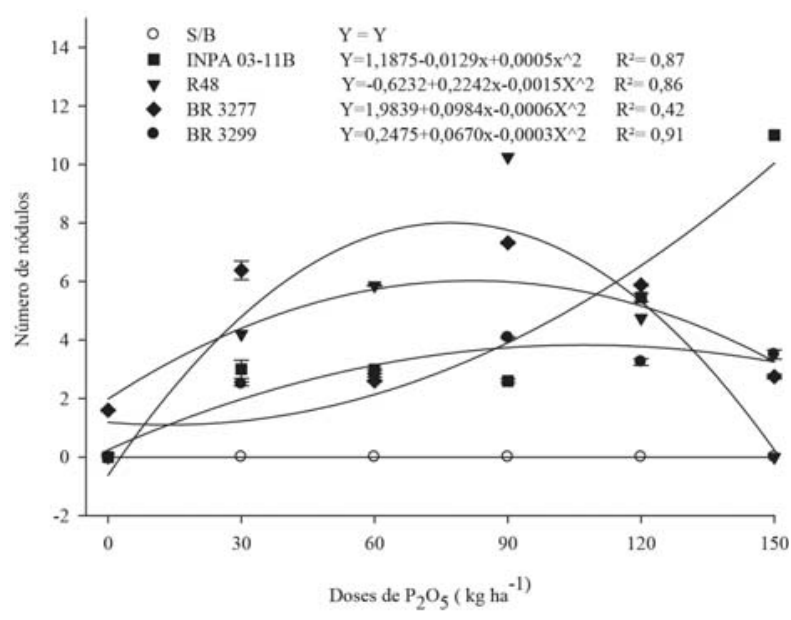

Figura 10 - Número de nódulos de planta de feijãocaupi, BRS Sempre Verde, em função das estirpes submetidas as doses crescentes de $\mathrm{P}_{2} \mathrm{O}_{5}$ no município de Gurupi- TO, 2015.
O contrário foi observado para a cv. BRS Nova Era, onde o tratamento sem bactérias não apresentou nodulação. A especificidade simbiótica de uma estirpe de bactéria fixadora de nitrogênio é representada pela sua habilidade em induzir a nodulação e fixar $\mathrm{N}_{2}$ quando associada a cultivares ou espécies hospedeira especifica (COSTA et al., 2011). Assim para uma mesma espécie, a eficiência pode depender da cultivar (FRANCO et al., 2002; XAVIER et al., 2006). O maior número de nódulos observados pelas estirpes INPA 03-11B (Figura 9) na cv. Nova Era e estirpe BR3299 na cv. Sempre verde (Figura 10) quando comparada com a testemunha, também foram observados por Marinho et al. (2014) corroborando com este trabalho.

Na cv. BRS Nova Era (Figura 11) foram observadas diferença para massa seca de nódulos para todas as estirpes avaliadas, sendo que a estirpe BR 3299 e INPA 03-11B condicionaram as maiores massa seca de nódulos na dose $30 \mathrm{~kg} \mathrm{ha}^{-1}$ de $\mathrm{P}_{2} \mathrm{O}_{5}$ com média estimada de 0,0128 e 0,0088 g respectivamente. Já estirpe R48, condicionou maior massa seca de nódulo na dose de $90 \mathrm{~kg} \mathrm{ha}^{-1} \mathrm{de}$ $\mathrm{P}_{2} \mathrm{O}_{5}$ com valor estimado de $0,0129 \mathrm{~g}$. No tratamento testemunha não foi observado massa seca dos nódulos já que não apresentou nodulação.

Gualter et al. (2011) avaliando a eficiência agronômica de estirpes de rizóbio em feijão caupi cultivado na região da Pré-Amazônia maranhense, observaram diferenças significativas nos tratamentos inoculados com as estirpes BR 3299 e INPA 03-11B, que promoveram maior número e massa de matéria seca de nódulos em comparação ao tratamento controle, nas duas épocas de avaliação resultado semelhante ao obtido neste trabalho.

Na cv. BRS Sempre Verde (Figura 12) tanto os tratamentos com inoculação quanto o tratamento testemunha (S/B) promoveram massa seca de nódulos. O contrário foi observado para cv. BRS Nova Era (Figura 11) onde o tratamento testemunha não condicionou massa seca de nódulos, isto pode estar relacionado à característica do genótipo em ter uma relação específica com as estirpes nativas.

Marinho et al. (2014) avaliando o desempenho em campo de novas cultivares de feijao-caupi inoculadas com estirpes de rizóbio eficientes na fixação de nitrogênio no semiárido brasileiro, verificaram que dependendo da cultivar para a mesma estirpe de bactéria obteve se resultados diferentes para massa seca de nódulos. 


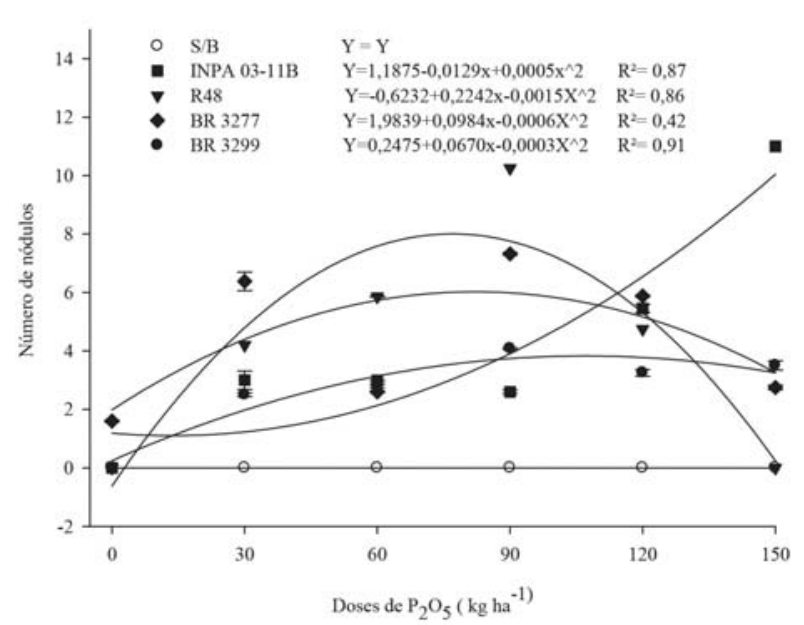

Figura 11 - Massa seca de nódulos de planta de feijãocaupi cv. BRS Nova Era, em função das estirpes submetidas as doses crescentes de $\mathrm{P}_{2} \mathrm{O}_{5}$ no município de Gurupi- TO, 2015.

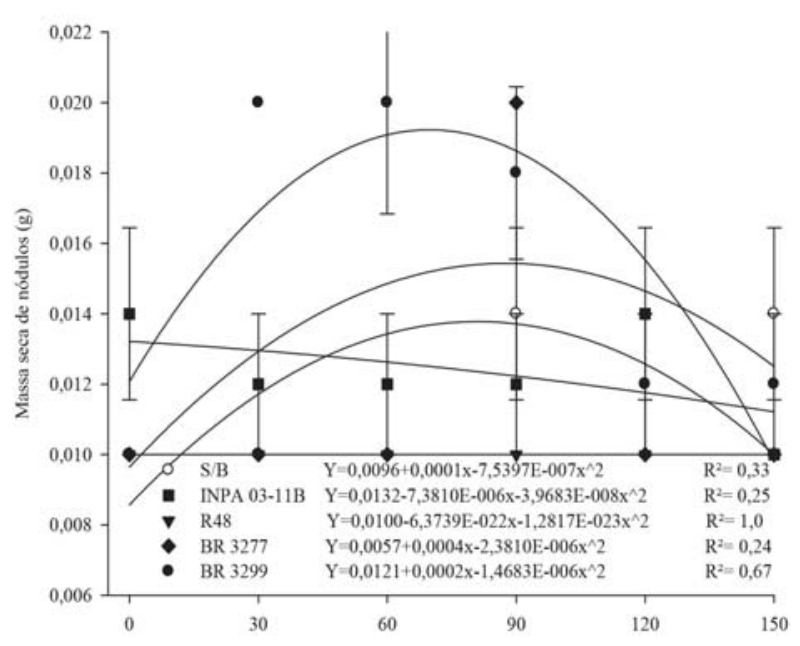

Figura 12 - Massa seca de nódulos de planta de feijãocaupi cv. BRS Sempre Verde, em função das estirpes submetidas as doses crescentes de $\mathrm{P}_{2} \mathrm{O}_{5}$ no município de Gurupi- TO, 2015.

Em relação as estirpes BR 3299 e BR 3277 obtiveram maior interação com a planta em relação as estirpes R 48 e INPA 03-11B para massa seca de nódulos, nas doses 30 e $90 \mathrm{~kg} \mathrm{ha}^{-1} \mathrm{P}_{2} \mathrm{O}_{5}$ para BR 3299 e na dose 90 para BR 3277 com médias estimadas de 0,0058 , $0,018 \mathrm{~g}$ respectivamente, para BR 3299 e $0,022 \mathrm{~g}$ para BR 3277.

\section{CONCLUSÕES}

As estirpes submetidas às doses de fósforo ou não proporcionaram acréscimo na altura de planta, diâmetro de colo, massa seca da parte aérea, massa seca da raiz para as duas cultivares de feijão-caupi estudas BRS Nova Era e BRS Sempre Verde.

As estirpes que proporcionaram os melhores efeitos para as características de biomassa de modo geral foram: a INPA 03-11B, bem como, a estirpe BR 3299 para a cultivar Nova Era em condições de casa de vegetação.

Para cultivar Sempre Verde a bactéria INPA 03-11B foi a que condicionou maior biomassa de modo geral.

As doses de fósforo que apresentaram a máxima eficiência agronômica para as duas cultivares quando associadas as estirpes avaliadas variaram de 50 a 80 $\mathrm{kg} \mathrm{ha}^{-1}$ de $\mathrm{P}_{2} \mathrm{O}_{5}$ para a maioria das variáveis estudadas nesse trabalho.

\section{LITERATURACITADA}

ABDEL-WAHAB, S.M.; HASSMAN, M.E.; ELWARRAKY, K.S.; SAFWAT, M.S.A. Evaluation of $\mathrm{N}_{2}$ - fixation of faba bean, chickpea and lentil as affected by phosphorus fertilization. African Crop Science Journal, v.1, n.1 p.71-73, 1994.

AMARAL, F.H.C.; NOBREGA, J.C.A.; MARTINS, R.N.L.; SILVA, A.F.T.; COSTA, E.M.; NOBREGA, R.S.A.; FILHO, J.F.L.; DIÓGENES, L.C.; PACHECO, L.P. Productivity and nodulation cowpea inoculated in function of phosphorus and potassium. Journal of Agricultural Science, v.5, n.11, p.86-92, 2013.

ANTÓN, M.R. Interacciones microorganismossuelo-planta en lapreservación del Medio Ambiente y la Salud. Real Academia Nacional Farmacia, v.70, n.3, p.743- 776, 2004.

AZEEM, B.; KUSHAARI, K.; MAN, Z. B.; Basit, A.; Thanh, T.H. "Review on materials \& methods to produce controlled release coated urea fertilizer." Journal of Controlled Release, v.181, n.1, p.11-21, 2014.

BASTOS, V.J.; MELO, D.A.; ALVES, J.M.A.; UCHÔA, S.C.P.; SILVA, P.M.C.; TEIXEIRA JUNIOR, D.L. Avaliação da fixação biológica de nitrogênio em feijão-caupi submetido a diferentes manejos da vegetação natural na savana de Roraima. Revista Agro@mbiente On-line, v.6, n.2, p.133-139, 2012. 
BONFIM-SILVA, E. M.; SILVA, T. J. A.; CABRAL, C. E. A.; GONÇALVES, J. M.; PEREIRA, M. T. J. Produção e morfologia da leguminosa java submetida a adubação fosfatada. Enciclopédia Biosfera, v.7, n.12, p. 1-10, 2011.

BURITY, H. A.; LYRA, M. C. C. P.; SOUZA, E. S. Efetividade da inoculação com rizóbio e fungos micorrízicos arbusculares em mudas de sabiá submetidas a diferentes níveis de fósforo. Pesquisa Agropecuária Brasileira, v. 35, n. 4, p. 801-807, 2000.

COSTA, E.M.; NÓBREGA, R.S.A.; MARTINS, L.V.; AMARAL, F.H.C.; MOREIRA, F.M.S. Nodulação e produtividade de Vigna unguiculata (L.) Walp. por cepas de rizóbio em Bom Jesus, PI. Revista Ciência Agronômica, v.42, n.1, p.1-7, 2011.

COUTINHO, P.W.R.; SILVA, D.M.S.; SALDANHA, E.C.M.; OKUMURA, R.S.; JÚNIOR, M.L.S. Doses de fósforo na cultura do feijão-caupi na região nordeste do Estado do Pará.Revista Agro@mbiente On-line, v.8, n.1, p.66-73, 2014.

CHAGAS JUNIOR, A.F.; OLIVEIRA, A. G.; REIS, H.B.; CHAGAS, L.F.B.; MILLER, L.O. Eficiência da inoculação combinada de rizóbio e Trichoderma spp. em diferentes cultivares de feijão-caupi (Vigna unguiculata) no cerrado (Savana Brasileira). Revista de Ciências Agrárias, v.37, n.1, p.20-28, 2014.

CRAVO, M.S.; SOUZA, B.D.L.; CUNHA, F.D.R. CAVALCANTE, E.S.; ALVES, J.M.A.; MARINHO, J.T.S.; VIEIRA JÚNIOR, J.R.; GONÇALVES, J.R.P.; FREITAS, A.C.R.; TOMAZETTI, M.A. Sistemas de cultivo. In: ZILLI, J.É.; VILARINHO, A.A.; ALVES, J.M.A. A cultura do feijão-caupi na Amazônia brasileira. Embrapa Roraima, 2009. p.59-104.

EMBRAPA - Empresa Brasileira de Pesquisa Agropecuaria. Sistema Brasileiro de Classificação de Solos. Embrapa Solos, p.74, 2013.

FERREIRA, D.F. SISVAR. a computer statistic alanalysis system. Ciência e Agrotecnologia, v.35, n.6, p.1039-1042, 2011.

FIGUEIREDO, M.V.B.; BURITY, H.A.; MARTINEZ, C.P. Drought stress response on some key enzymes of cowpea (Vigna unguiculata L. Walp.) nodule metabolism. World Journal Microbiology Biotechnologia, v.23, n.2, p.187-193, 2007.
FRANCO, M. C.; CASSINI, S.T. A.; OLIVEIRA, V. R.; VIEIRA, C.; TSAI, S.M. Nodulation in Andean and Mesoamerican cultivars of dry bean. Pesquisa Agropecuária Brasileira, v.37, n 8, p.1145-1150, 2002.

GUALTER, R. M. R; BODDEY, R. M; RUMJANEK, N. G; FREITAS, A. C. R; XAVIER, G. R. Eficiência agronômica de estirpes de rizobio em feijão-caupi cultivado na região da Pré-Amazonia maranhense. Pesquisa Agropecuária Brasileira, v.46, n.3, p.303-308, 2011.

GUEDES, G.N.; SOUZA, A.S.; LIMA, A.S.; ALVES, L.S. Eficiência agronômica de inoculantes em feijão-caupi no Município de Pombal - PB. Revista Verde, v.5, n.10, p.82-89, 2010.

KIMANI, J.M.; DERERA, J. Combining ability analysis across environments for some traits in dry bean (Phaseolus vulgaris L.) under low and high soil phosphorus conditions. Euphytica, v.166, n.1, p.1-13, 2009.

MARINHO, R.C.N.; NÓBREGA, R.S.A.; ZILLI, J.E.; XAVIER, G.R.; SANTOS, C.A.F.; AIDAR, S.T.; MARTINS, L.M.V.; FERNANDES JUNIOR, P.I. Field performance of new cowpea cultivars inoculated with efficient nitrogen-fixing rhizobial strains in the Brazilian Semiarid. Pesquisa Agropecuária Brasileira, v.49, n.5, p.395-402, 2014.

MOREIRA, F.M.S.; SIQUEIRA, J.O. Microbiologia e bioquímica do solo. 2.ed. Lavras, MG: Ed. UFLA, 729p. 2006.

NYOKI, D.; NDAKIDEMI, P.A. Economic benefits of Bradyrhizobium japonicum inoculation and phosphorus supplementation in cowpea (Vigna unguiculata (L) Walp) grown in northern Tanzania. American Journal of Research Communication, v.1, n.11, p.173-189, 2013.

OLIVEIRA, D.P. Adubação nitrogenada, inoculação com estirpes de rizóbios e tratamentos fungicidas de sementes em feijoeirocomum cv. BR SMG Madrepérola. 180f. Tese (Doutorado em Produção Vegetal). Universidade Federal de Lavras, Lavras, MG, 2013. 
OLIVEIRA, G.A.; ARAÚJO, W.F.; CRUZ, P.L.S.; SILVA, W.L.M.; FERREIRA, G.B. Resposta do feijão-caupi as lâminas de irrigação e as doses de fósforo no cerrado de Roraima. Revista Ciência Agronômica, v.42, n.4, p.872-882, 2011.

OKELEYE, K. A.; OKELANA, M. A. Effect of phosphorus fertilizer on nodulation, growth and yield of cowpea (Vigna unguiculata) varieties. Indian Journal of Agricultural Sciences, v. 67, n. 1,p. 10-12, 1997.

PASTORINI, L.H.; BACARIN, A.M.; LOPES, F.N.; LIMA, S.G.M. Crescimento inicial de feijoeiro submetido a diferentes doses de fósforo em solução nutritiva. Revista Ceres, v.47, n.270, p.219-228, 2000.

ROCHA, W.S. Inoculação e doses de fósforo em feijão caupi no sul do Estado do Tocantins em casa de vegetação. 59f. Dissertação (Mestrado em Produção Vegetal). Universidade Federal do Tocantins, Gurupi-TO, 2016.
SILVA, E.F.L.; ARAÚJO, A.S.F.; SANTOS, V.B.; NUNES, L.A.P.L.; CARNEIRO, R.F.V. Fixação biológica do $\mathrm{N}_{2}$ em feijão-caupi sob diferentes doses e fontes de fósforo solúvel. Bioscience Journal, v.26, n.3, p.394-402, 2010.

SOARES, A.L.L.; PEREIRA, J.P.A.R.; FERREIRA, P.A.A.; VALE, H.M.M.; LIMA, A.S.; ANDRADE, M.J.B.; MOREIRA, F.M.S. Eficiência agronômica de rízobios selecionados e diversidade de populações nativas nodulíferas em perdões (MG). Revista Brasileira de Ciência do Solo, v.30, n.1, p.803-811, 2006.

SOUTO, J.S.; OLIVEIRA, F.T.; GOMES, M.M.S.; NASCIMENTO, J.P.; SOUTO, P.C (. Efeito da aplicação de fósforo no desenvolvimento de plantas de feijão guandu Cajanus cajan (L) Millsp). Revista Verde, v.4, n.1, p.135-140, 2009.

XAVIER, G.R.; MARTINS, L.M.V.; RIBEIRO, J.R.A.; RUMJANEK, N.G. Especificidade simbiótica entre rizóbios e acessos de feijão-caupi de diferentes nacionalidades. Caatinga, v.19, n.1, p.25-33, 2006.

Recebido para publicação em 29/01/2019 e aprovado em 19/06/2019. 